\title{
Replanejamento Urbano Nas Proximidades do Bairro São João no Município de Pato Branco - PR, Baseado em Critérios de Sustentabilidade
}

Urban replanning on São João neightborhood proximities in Pato Branco -PR, based on susteinability concepts

Nueva planificación urbana en las proximidades del barrio São João en Pato Branco -PR, basado en criterios de sostenibilidad

\section{Lucas Gabriel Winter Mestrando, UTFPR, Brasil Igwinter@hotmail.com}

Bruno Soares Martins Mestrando, UTFPR, Brasil brunomartins.arquiteto@gmail.com

Daise Martinazzo Especialista, UNIPAR, Brasil daise_martinazzo@hotmail.com 


\title{
1 INTRODUÇÃO
}

Inicialmente se faz necessário definir o tema: urbanismo sustentável.

\begin{abstract}
A sustentabilidade urbana é um debate que surge da necessidade de entendermos o conjunto de problemas da qualidade de vida urbana, tais como: alterações climáticas, esgotamento de energias fósseis e minerais, desmatamento desenfreado, violência, desigualdade social, transporte público escasso, entre outros. São inúmeras as questões levantadas nesse contexto, assim como a pluralidade com que o termo é empregado na literatura e documentos, pois, além da discussão urbana inserida na dimensão ambiental, o conceito incorpora as dimensões econômica, social, cultural e política. (SAMPAIO, 2009).
\end{abstract}

Para ROGER-MACHART (1997), uma cidade sustentável é aquela que, sem esgotar os recursos naturais do planeta que serão utilizadas pelas futuras gerações, completa às necessidades de seus habitantes atuais. Essa proposta só pode ser atingida se houver uma maximização da circularidade dos recursos, otimização da eficiência e gerenciamento de meios.

Segundo RUANO (2000), o Urbanismo Sustentável é uma nova disciplina. Esta articula complexas variáveis, com múltiplos conceitos, escalas, responsabilidade climática e cultural, inovação da tecnologia construtiva, estratégias formais e estilísticas, introdução de técnicas representativas e de recursos alternativos para obtenção de energia, uso de ferramentas tecnológicas no campo da informática, das telecomunicações e dos meios de comunicações. Tudo isso incorpora uma aproximação ao desenho urbano, com uma visão associada e integrada, ocasionando a superação da divisão tradicional do urbanismo e seus discernimentos formais e estilísticos.

Pode-se compreender então o urbanismo sustentável como uma série de medidas ecologicamente corretas: seja pela preferência dos deslocamentos a pé, pela correta gestão de água e resíduos, pela infraestrutura de baixo impacto ambiental, dentre outros fatores.

\section{OBJETIVOS}

O objetivo do trabalho é de realizar um novo projeto urbanístico na área sinalizada, baseado em critérios de sustentabilidade.

\section{METODOLOGIA / MÉTODO DE ANÁLISE}

A área destinada à proposta do anteprojeto urbano está localiza a oeste da cidade de Pato Branco, no limite da malha urbana, onde atualmente estão localizados o bairro São João, Alto da Glória e o conjunto habitacional São Pedro. Possui aproximadamente 310 hectares, e se configura com a característica de um vale, haja vista que nos extremos leste e oeste, temos as cotas de nível mais altas e no eixo norte sul, as mais baixas.

No eixo norte sul é onde se concentra a maior parte dos trechos a serem preservados e também onde localiza-se o principal rio que permeia a área em quase toda a sua extensão. 


\section{rólum Ambiental

A figura abaixo ilustra em amarelo o local do anteprojeto, considerando as 4 coordenadas dos vértices no sistema UTM.

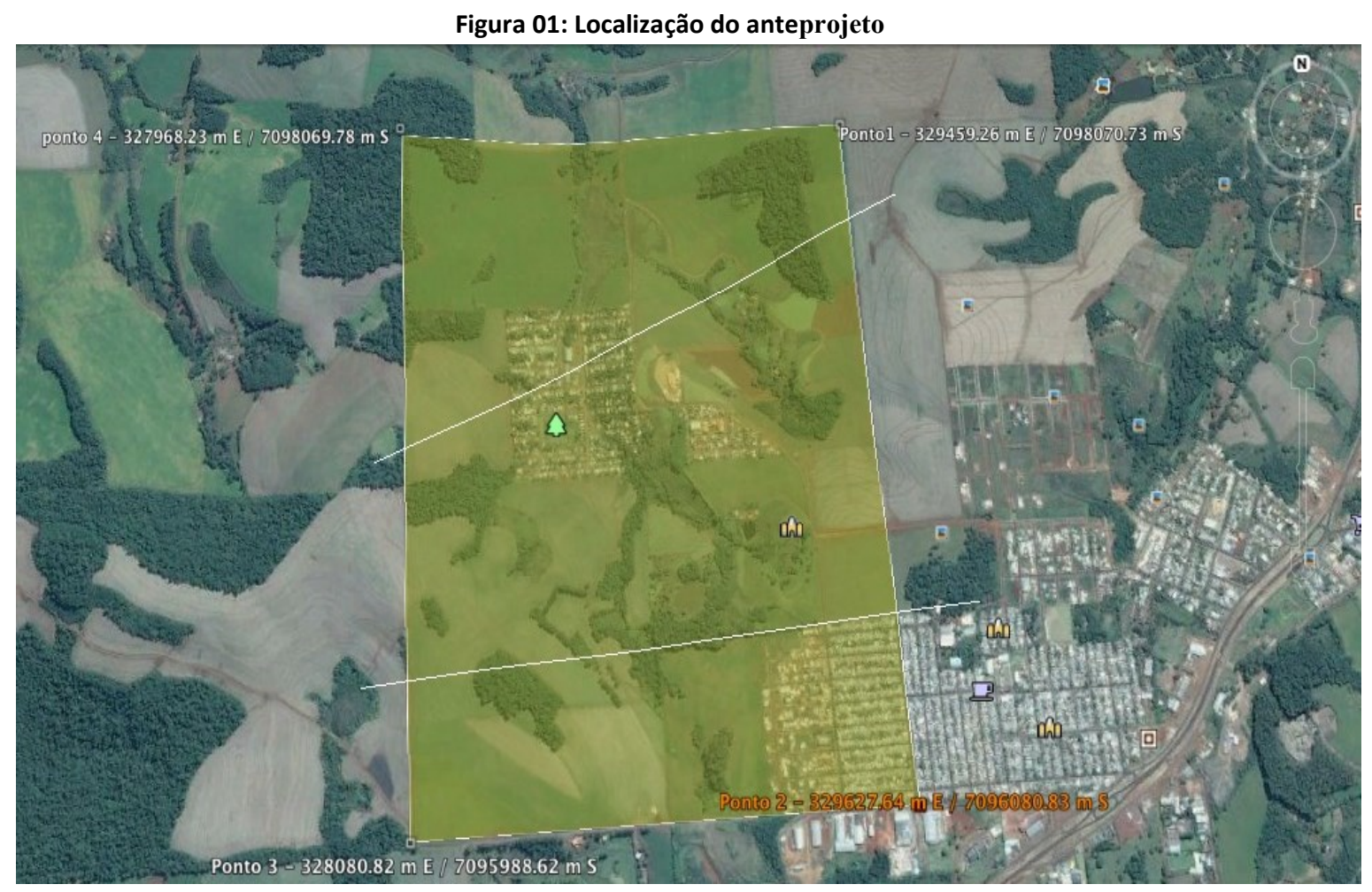

Fonte: OS AUTORES, 2016.

Sendo assim:

Ponto 01 - superior direito: 329459.26 Oeste e 7098070.73 Sul;

Ponto 02 - inferior direito: 329627.64 Oeste e 7096080.83 Sul;

Ponto 03 - inferior esquerdo: 328080.82 Oeste e 7095988.62 Sul;

Ponto 04 - superior esquerdo 327968.23 Oeste e 7098069.78 Sul.

Tratando-se do meio urbano existente, foi verificado in loco que o traçado urbano não contribui para a realização de atividades sem o uso de veículos motorizados, existem ruas com inclinações elevadas e a grande maioria destas não possui passeio público. O meio urbano atual não levou em consideração as condições topográficas do local. 


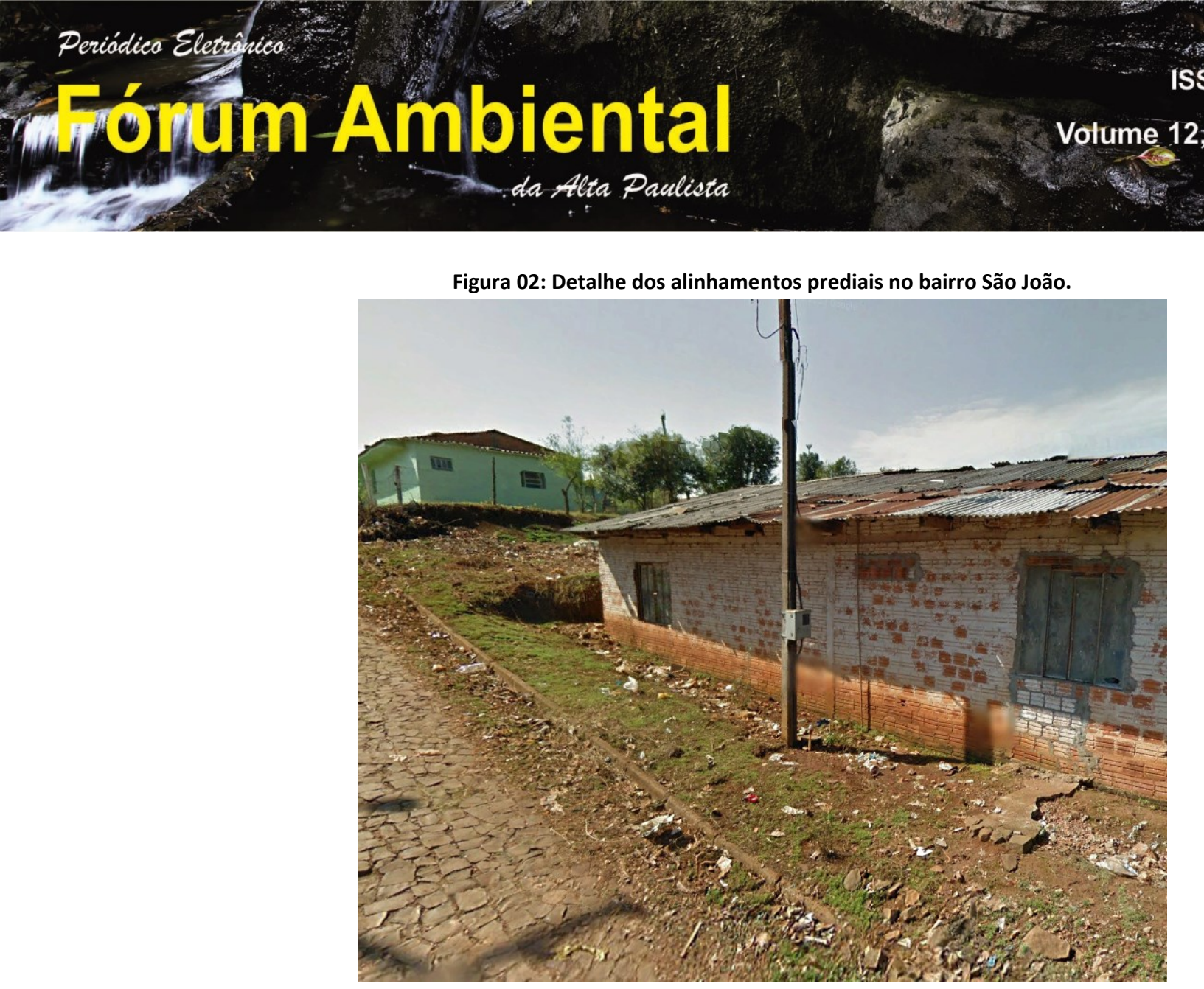

Fonte: OS AUTORES, 2016.

Figura 03: Detalhe das vias do bairro São João.

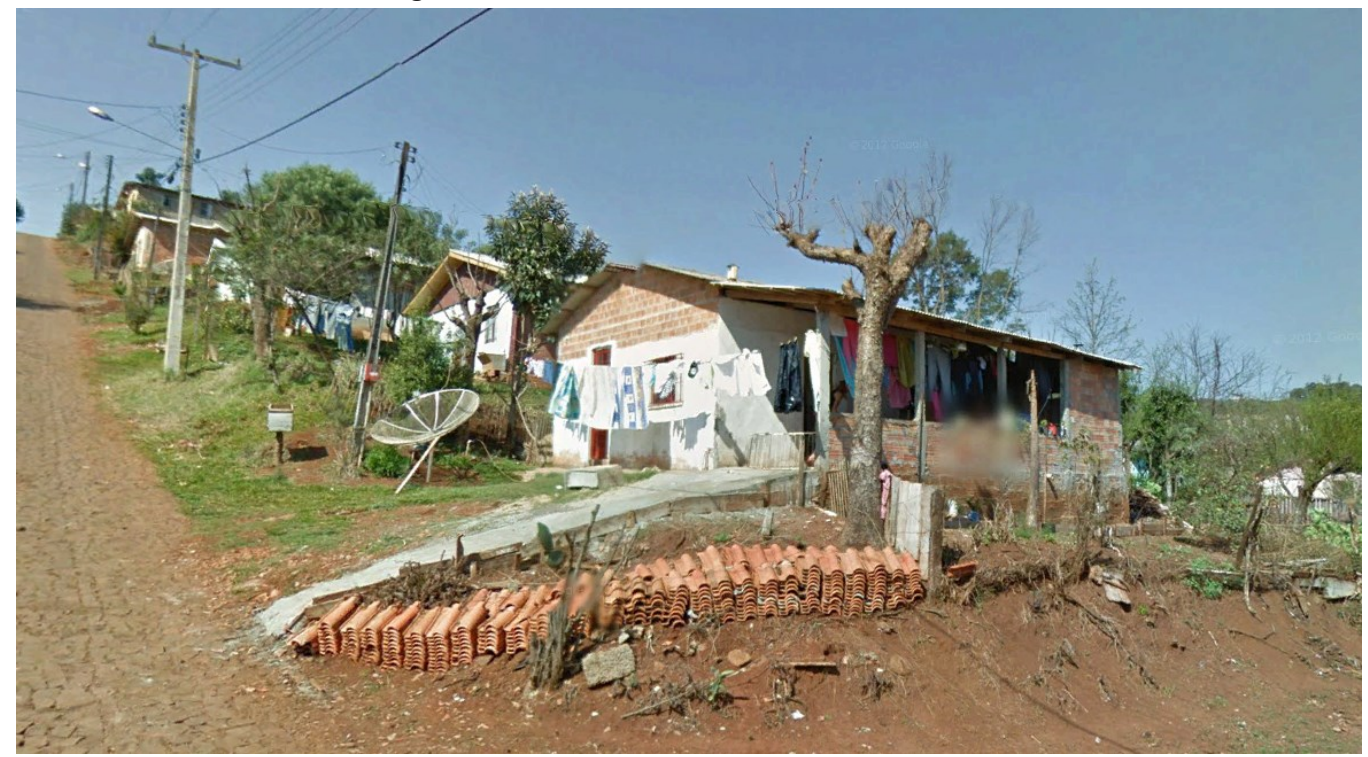

Fonte: OS AUTORES, 2016. 


\subsection{CONDIÇÕES GEOGRÁFICAS}

Para Mota (1999), as formas de relevo de uma determinada área exercem grande influência no seu processo de ocupação, e comumente são bastante alteradas pelo mesmo.

A topografia influencia o processo de urbanização de forma expressiva, usar um terreno com declividade maior que o apropriado para ocupação urbana, pode causar deslizamentos pelos problemas de instabilidade (MOTA, 1999).

O autor ainda afirma que o homem consegue, em alguns casos, vencer a obstáculos da topografia não favorável, porém isto é feito com a movimentação de terras e por outras ações sobre a natureza. Estas ações podem ser fatores determinantes para a paisagem gerando prejuízos à qualidade do meio ambiente. (MOTA, 1999).

O artigo 3o da Lei Federal o 6.766 de 19 de dezembro de 1979 diz: (...) Não será permitido o parcelamento do solo em terrenos com declividade igual ou superior a 30\% (trinta por cento) (...). Observando a diversidade de problemas causados pela ocupação em áreas com declividades superiores ao citado na lei, foi elaborado um mapa de declividades, sendo assim destinado à APP (Área de Preservação Permanente) as áreas acima do limite estabelecido. No mapa que segue abaixo, em vermelho escuro estão as áreas irregulares, ficando assim evidente os locais impróprios para ocupação. As áreas com tons de verde, amarelo e laranja estão dentro da margem permitida por lei. Para a elaboração de tal mapa foi utilizado o software ArcMap, utilizando como base a topografia mapeada pela Prefeitura Municipal de Pato Branco. 
Permanente, em zonas rurais ou urbanas, para os efeitos desta Lei: 30 (trinta) metros de ambos os lados, para os cursos d'água de menos de 10 (dez) metros de largura (...). A largura da faixa de preservação aumenta de acordo com a largura do córrego. Neste caso não há a incidência de córregos com larguras superiores de 10 metros. A partir do mapa hidrográfico fornecido pela Prefeitura Municipal de Pato Branco, foi possível organizar os elementos hídricos do local e pré-estabelecer a proposta de arruamento. Na figura abaixo, as linhas em verde claro ilustram a proposta de arruamento e distribuição de lotes.

Figura 05: Mapa de declividades

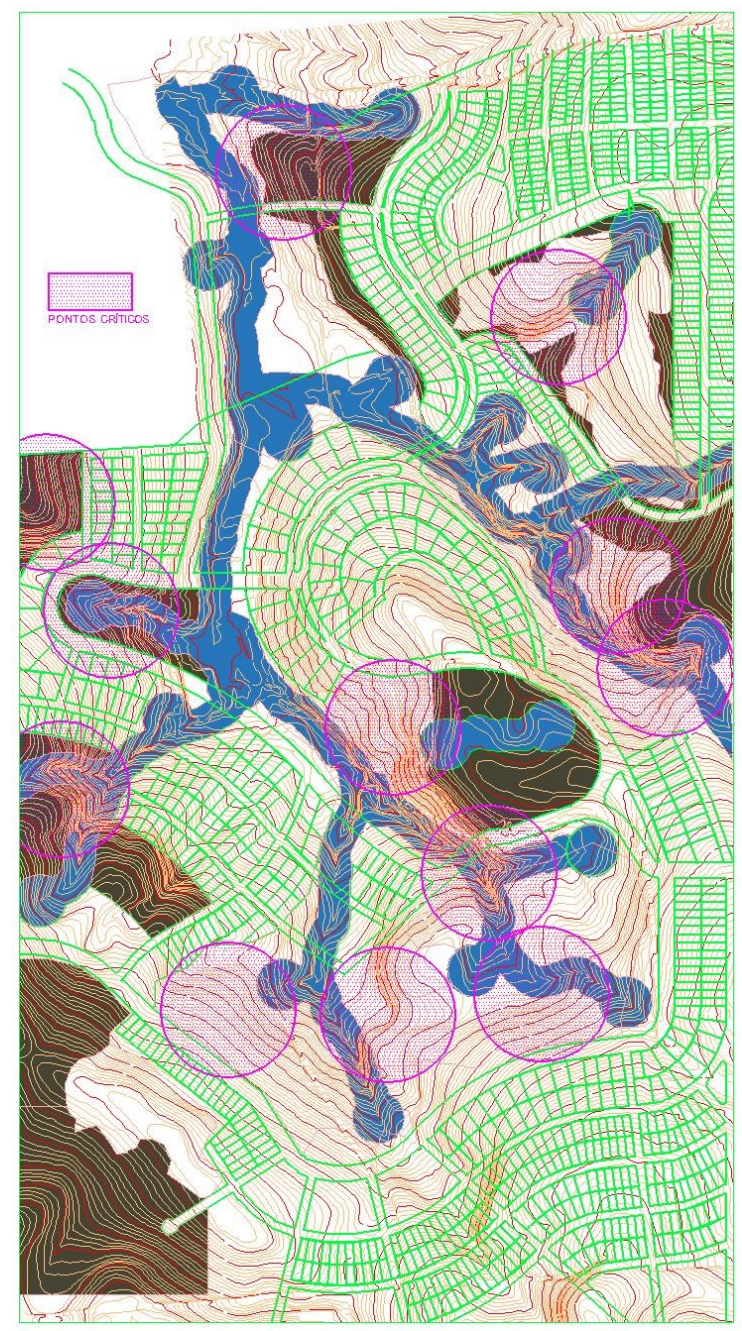

Fonte: OS AUTORES, 2016.

Da mesma maneira estabelecida para os cursos d'água o inciso 20 do artigo 40 da mesma lei diz que: (...) serão destinados à preservação as áreas no entorno das nascentes e dos olhos d'água perenes, qualquer que seja sua situação topográfica, no raio mínimo de 50 (cinquenta) metros (...). A figura 05 destaca em azul as áreas de preservação ao longo de cursos d'agua e nascentes sendo 30 de largura e 50 metros de raio respectivamente. Foi realizado um cruzamento com o mapa de declividades e destacou-se na cor magenta as áreas que também 
deverão ser destinadas à preservação devido a inclinação superior a 30\%. Verificou-se que na maioria dos casos as áreas de preservação estabelecidas por ambas as leis coincidem. Em todas estas áreas citadas por ambas as leis não foram projetados lotes nem vias.

\subsection{PROPOSTA URBANÍSTICA}

Cada projeto urbano necessita uma análise distinta dos demais pois as condições do meio sempre se diferem.

Para FAAR (2013), a maioria das pessoas caminha uma distância média de 400 metros antes de optar por dirigir ou usar uma bicicleta, essa dimensão é uma constante na forma como as pessoas tem agido por séculos. Ou seja, se conseguíssemos satisfazer nossas necessidades dentro dessa distância, o uso do transporte individual seria drasticamente diminuído. Uma variedade de usos permite que os moradores morem, trabalhem, se divirtam, se exercitem, façam compras e satisfaçam suas necessidades a pé. Uma variedade de tipos de edificações permite que as pessoas com diferentes rendas ou estilos de vida vivam no mesmo bairro sem prejuízo para seu caráter ou qualidade.

Um dos conceitos do urbanismo sustentável é fazer a diversidade de uso, ou seja, mesclar moradia e comércio no mesmo bairro, fato este que contrasta da maioria dos casos de bairros brasileiros, principalmente aqueles voltados para moradia popular.

O desenho urbano orientado para os deslocamentos a pé pode reduzir significativamente 0 uso de veículos individuais e até mesmo dos coletivos. Quando se trata do termo mobilidade urbana, um ponto que merece destaque é a implantação de setores de uso misto: residência, lazer e trabalho no mesmo bairro. Em altas densidades urbanas, esta sugestão torna-se uma poderosa ferramenta, pois as pessoas podem realizar todas as suas atividades cotidianas em pequenas distâncias (FAAR, 2013).

O urbanismo sustentável se caracteriza por alta quantidade de unidades de habitação por hectare. Mais pessoas vivendo em menos espaço de solo. Neste quesito a verticalização se torna uma ferramenta de grande valia.

Atendendo os conceitos de verticalização e uso misto, foi conceituado um setor comercial no anteprojeto, onde supostamente estariam localizados prédios de maior porte. Baseado nisso, é coerente a realização de um estudo solar para verificar onde estão os locais que causariam menor impacto no entorno, principalmente nos meses de inverno onde o sol torna-se uma ferramenta de extrema necessidade para os habitantes do bairro. Os exemplos clássicos da falta de estudo solar na implantação de edificações são os prédios beira-mar na cidade de Balneário Camboriú, causando sombras em alguns horários para os banhistas.

A proposta parte do princípio de organizar os edifícios de maior gabarito nas cotas mais baixas do anteprojeto, assim, o impacto causado pelo sombreamento é menor, como pode ser analisado nas imagens do estudo solar que seguem abaixo. Realizou-se o estudo tomando em consideração a localização geográfica do local no dia 23 de junho de 2016. As quadras foram demarcadas na cor vermelha, e as APPs em cor cinza. 


\section{Periádica Eletrốnica

Figura 06: Estudo de insolação às 09 horas.

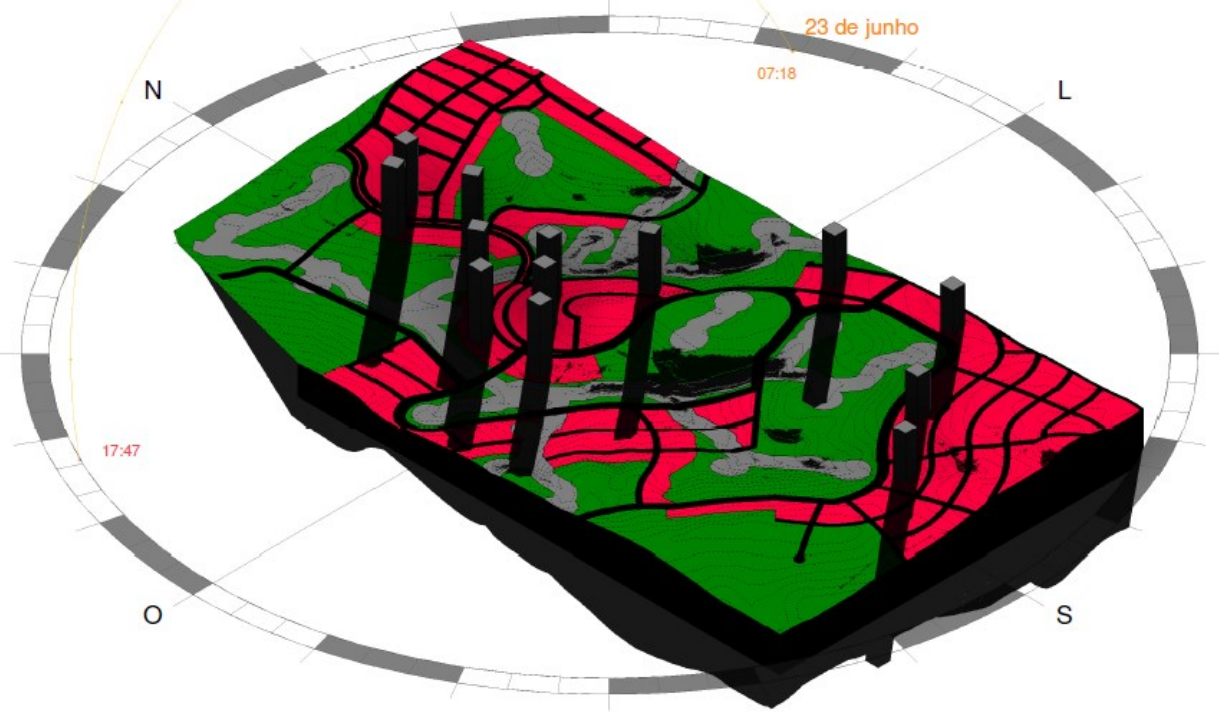

Fonte: OS AUTORES, 2016.

Figura 07: Estudo de insolação às 16 horas.

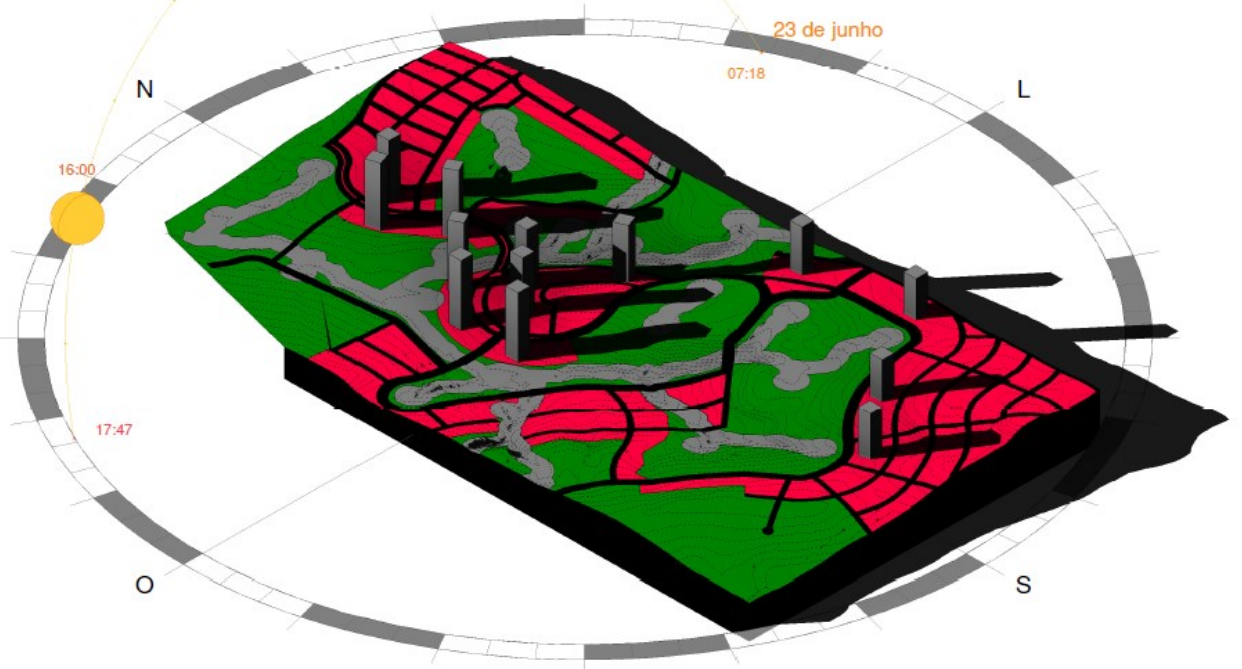

Fonte: OS AUTORES, 2016.

A partir dos conceitos citados realizou-se a setorização do novo anteprojeto, conforme distribuição abaixo. As ruas buscam seguir o sentido natural da topografia, evitando assim 
cortes ou aterros na paisagem e evitando ruas demasiadamente acidentadas, da mesma maneira que transferem essas qualidades aos lotes. Pelo fato das ruas seguirem o sentido da topografia, a grande maioria das ruas foi projetada no formato curvo, totalmente diferente das ruas retas comumente encontradas nas cidades brasileiras. Conforme imagem abaixo, as quadras foram detalhadas conforme legenda, as áreas de APP em preto e as demais áreas brancas seriam destinadas a conservação natural e reflorestamento.

Figura 08: Zoneamento proposto.

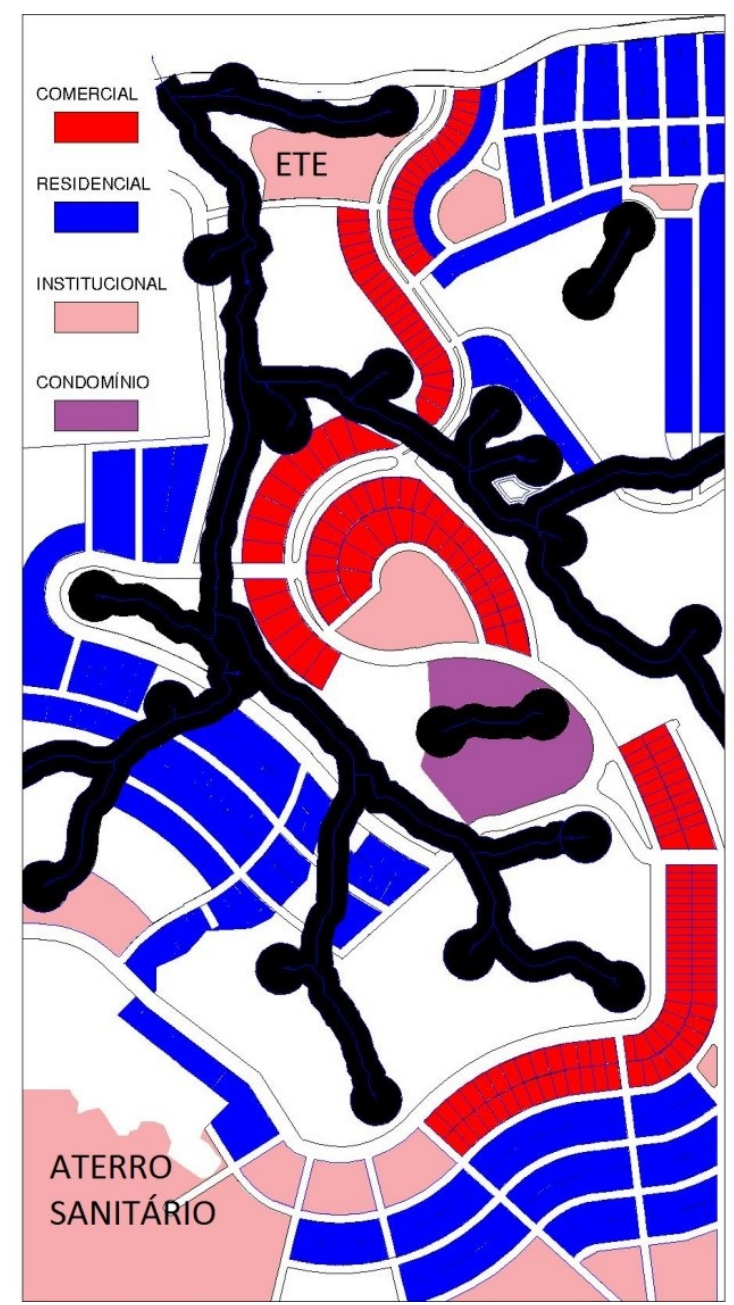

Fonte: OS AUTORES, 2016.

Zona comercial (em vermelho): caracterizado por lotes de maior área e potencial construtivo, foram setorizados ao longo do parque linear proposto ao longo das APP's, e mais próximo das cotas mais baixas, também, sendo um elo que corta o anteprojeto de uma ponta à outra, para esta área foi proposta uma via mestra de 30 metros de largura, pois espera-se que o tráfego de usuários seja mais intenso que nos setores apenas residenciais. 
Figura 09: Proposta para a via principal

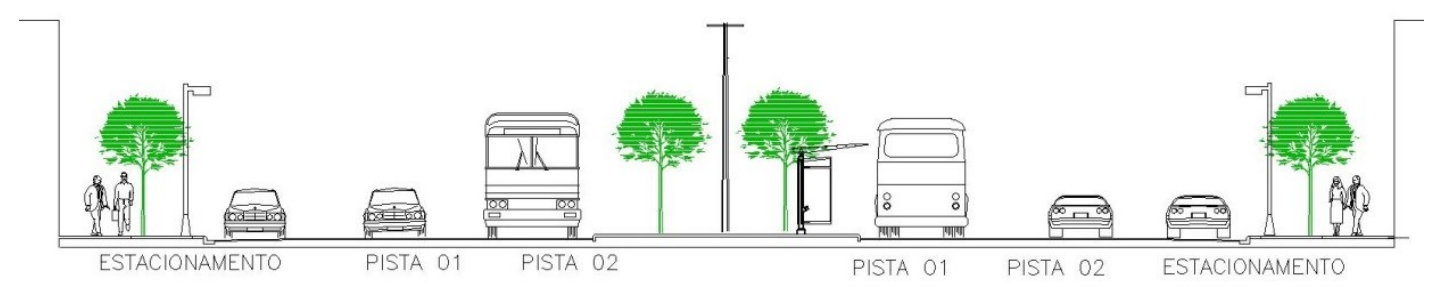

Fonte: OS AUTORES, 2016.

Zona residencial (em azul): foi distribuída ao longo de todo o anteprojeto, concentrando setores com diferentes dimensões de terreno, para estas áreas foram propostas vias de 16 metros de larga, sendo 8 metros de caixa e 4 de passeios para cada lado.

Figura 10: Proposta para as vias residenciais

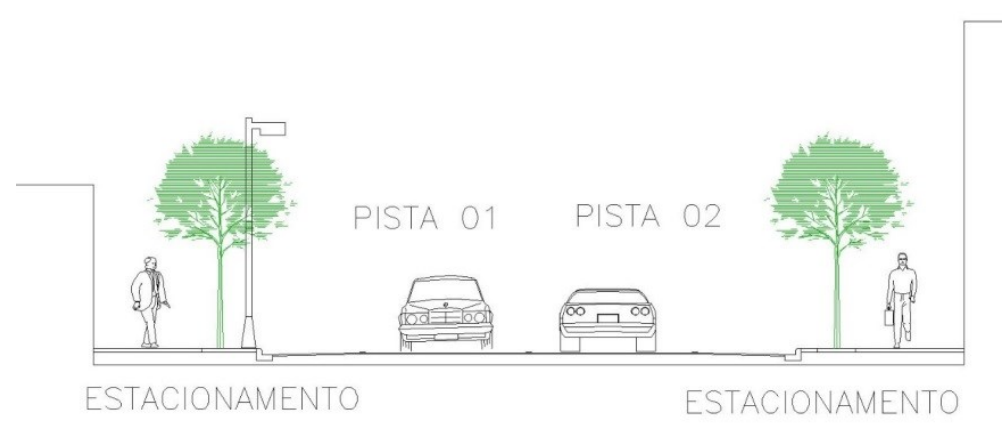

Fonte: OS AUTORES, 2016.

Zona institucional (em rosa) - tem o intuito em setorizar de certa forma segregada pelo parque linear, é justamente pelo fato de serem equipamentos de uso cotidiano, que fariam com que as pessoas se deslocassem pelo local, interagindo com o parque linear e com os demais equipamentos públicos.

Foi previsto um aterro sanitário exclusivo para o bairro que foi localizado de forma a não integrar a paisagem, ficando posicionado após o divisor de águas que se encontra a sudoeste e também protegido por área de vegetação. $O$ fator determinante para a locação do aterro foi o gráfico da direção dos ventos do Município de Pato Branco, ele demonstra que os ventos tendem a soprar sentido sul e sudeste, transferindo assim os odores provenientes do aterro sanitário para um ponto oposto ao perímetro urbano. 
Figura 11: Direção dos ventos de Pato Branco.

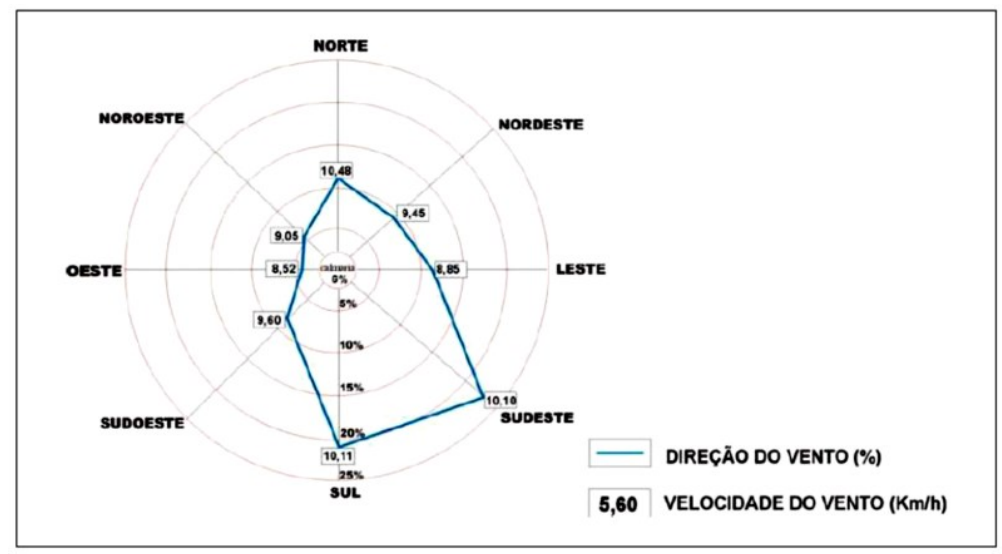

Fonte: TABALIPA, 2002.

No aspecto de saneamento, foi prevista uma estação de tratamento de esgoto para o anteprojeto em uma das áreas mais baixas em função da topografia, com a finalidade de que todo o escoamento possa acontecer por gravidade, racionalizando o uso deste espaço e fomentando os critérios ambientais.

\section{RESULTADOS E CONCLUSÕES}

Baseado no novo desenho urbano na área de 310 hectares, calculou-se os novos resultados de densidade urbana, considerou-se 3 pessoas por terreno nas zonas residenciais (residências unifamiliares) e 30 pessoas para as zonas comerciais (residências multifamiliares), chegando assim em um total estimado de 8000 pessoas.

\begin{tabular}{|c|c|c|c|c|c|}
\hline \multicolumn{6}{|c|}{ Quadro 01: Dimensionamento populacional } \\
\hline \multicolumn{2}{|c|}{ QUADRAS } & ZONEAMENTO & LOTES & $\begin{array}{l}\text { QUANT. } \\
\text { PESSOAS }\end{array}$ & POPULAÇÃO \\
\hline \multicolumn{2}{|c|}{8} & COMERCIAL & 189 & 30 & 5670 \\
\hline \multicolumn{2}{|c|}{19} & RESIDENCIAL NORTE & 362 & 3 & 1086 \\
\hline \multicolumn{2}{|c|}{12} & RESIDENCIAL OESTE & 197 & 3 & 591 \\
\hline \multicolumn{2}{|c|}{9} & RESIDENCIAL SUL & 208 & 3 & 624 \\
\hline & ------ & INSTITUCIONAL & 13 & & \\
\hline TOTAIS & & 969 & & 7971 \\
\hline
\end{tabular}

Fonte: OS AUTORES, 2016. 
Verificou-se que o desenho urbano proposto é totalmente diferente das condições existentes no local, estando o desenho urbano atual incoerente com os conceitos de urbanismo sustentável.

\section{REFERÊNCIAS BIBLIOGRÁFICAS}

BRASIL. Lei $n^{\circ}$ 6.766, de 19 de dezembro de 1979.

BRASIL. Lei no 12.651, de 25 de maio de 2012.

FAAR, D. Urbanismo Sustentável, desenho urbano com a natureza. Tradução Alexandre Salvaterra. Porto Alegre: Editora Bookman, 2013. 326p.

MOTA, Suetônio. Urbanização e Meio ambiente. Rio de Janeiro. ABES, 1999.

ROGER-MACHART, C. The sustainable city - myth or reality? In: T\&CP, p. 53-55, fev. 1997.

RUANO, M. Ecourbanism: Sustainable human settlements: 60 cases studies. Barcelona: Editorial Gustavo Gilli, 2000.

SAMPAIO, Danusa Teodoro. Sustentabilidade Urbana: Conceitos e Controvérsias. Dissertação (Mestrado em Engenharia Urbana) - Universidade Federal de São Carlos. São Carlos, 2009.

TABALIPA, Ney Lyzandro. Proposta para desenvolvimento urbano do município de Pato Branco, Paraná, baseada em critérios geológicos e geomorfológicos. Dissertação (Mestrado em Geologia) - Universidade Tecnológica Federal do Paraná. Curitiba, 2002. 